\title{
Alarm growing over limited access to BC pharma data
}

$\mathrm{E}$ leven months after the British Colombia Ministry of Health began purging staff and scientists amidst an investigation into the management of drug data from its province-wide pharmaceutical database, lawsuits against the ministry continue to pile up and alarm is growing among research leaders.

The abrupt staff dismissals, hobbling drug-safety watchdogs, are one problem, the research leaders note; another issue is that pending the investigation's outcome, the ministry has severely restricted access to data from its PharmaNet databases - North America's most comprehensive source of population-wide drug safety and efficacy data drawn from all pharmacists, patients and clinicians throughout BC.

By curbing access to the database for nearly a year, since last summer, the $\mathrm{BC}$ government is inflicting severe harm on numerous pivotal drug-safety studies, warns Dr. David Henry, chief executive officer of the Institute for Clinical Evaluative Sciences in Toronto, Ontario, where data from BC are used in collaborations such as the Canadian Network for Observational Drug Effect Studies. "The most comprehensive data in Canada has been denied to us," Henry says, noting that the $\mathrm{BC}$ government has failed to respond to repeated inquiries from alarmed scientists across Canada. "We've not been given a way forward."

Dr. Jim Wright, director of the University of British Columbia's (UBC) Therapeutics Initiative in Vancouver, a drug-safety research centre that has been denied access to PharmaNet data pending the outcome of the Ministry's investigation, describes the cessation of data access as a "very disturbing" development that has denied research results to patients and physicians from a series of studies into the safety of widely used pharmaceuticals. Researchers familiar with the Therapeutics Initiative say worries are growing about its ability to survive without access to data.

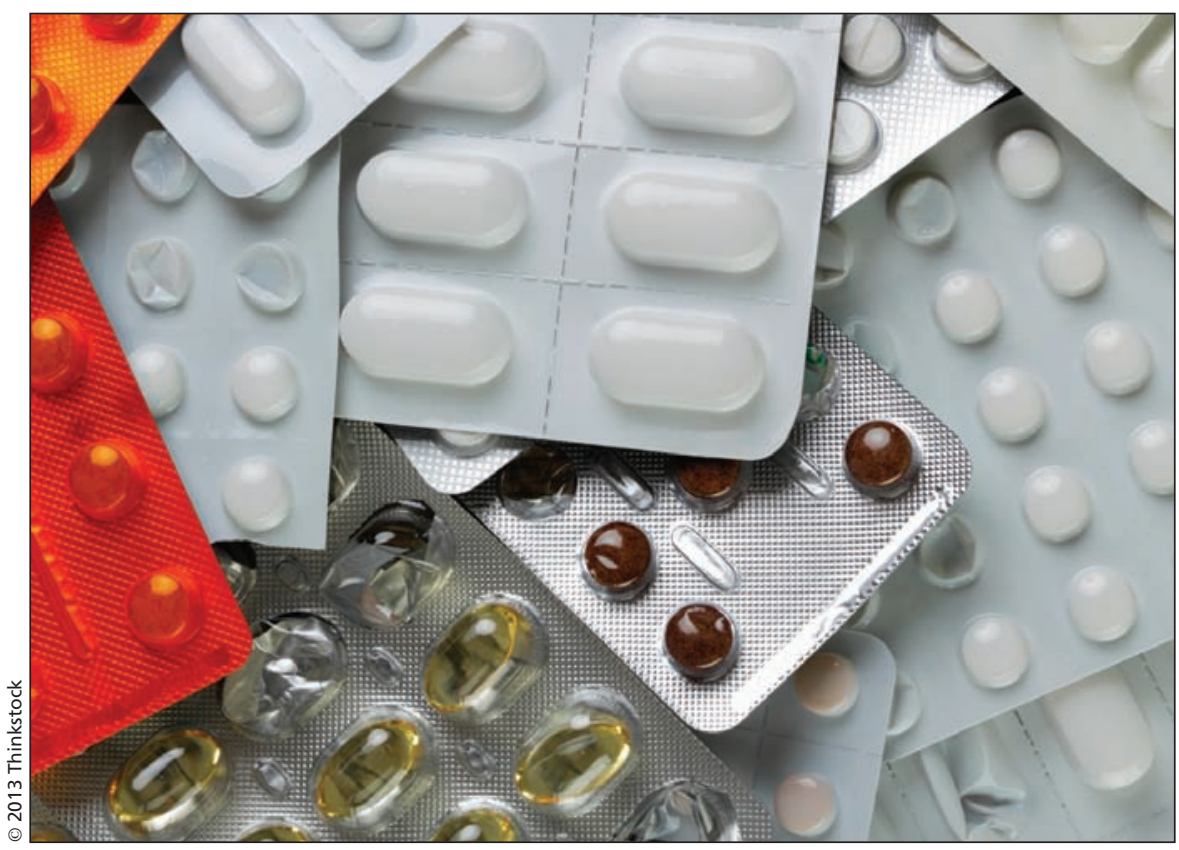

By curbing access to the database for nearly a year, the BC government is inflicting severe harm on numerous pivotal drug safety studies, a research leader warns.

So far, the BC government has revealed little about the investigation that prompted it to remove research leaders and curtail data access for a suite of studies underway into the safety of numerous classes of drugs.

BC Minister of Health Margaret MacDiarmid announced in September that the Royal Canadian Mounted Police (RCMP) had been asked to investigate alleged inappropriate conduct, contracting and data-management practices.

But according to Sergeant Duncan Pound of RCMP "E" Division Criminal Operations Federal Policing in Surrey, $\mathrm{BC}$, the ministry had yet to fully prepare the case when MacDiarmid announced the investigation. Contacted this week, Pound would not confirm whether or not the force is pursuing the ministry's request for an investigation.

In January, MacDiarmid clarified that the drug data at issue in the ministry's investigation were de-identified to protect the identity of patients, and have been used only for research. Contacted earlier this week, Ministry spokesman Ryan Jabs said there was nothing further to add to MacDiarmid's previous statements.

Seven legal actions have been filed by drug researchers working with PharmaNet data who have been suspended or terminated since July 2012. The latest was announced by Rebecca Warburton, who was codirector of research and evidence development in the Policy, Outcomes Evaluation and Research Branch of the Ministry's Pharmaceutical Services Division from August 2009 until October 2012.

All seven legal claims charge that the ministry acted without just cause, without due process and without awaiting conclusions from its own investigation before acting against employees.

Warburton, 60, was suspended without pay last July and dismissed from her job at the ministry - which she held alongside a professorship in health economics at the University of Victoria's School of Public Administration - in October. Her lawsuit claims the ministry has "failed and 
refused to provide ... particulars of the allegations being made against her."

Warburton's wording closely resembles that in a suit filed last September by Malcolm Maclure, 60, who, until being terminated last summer, served with Warburton as codirector of research and evidence development in the Pharmaceutical Services Division. Like Warburton and two other government employees, Bob Hart and Ron Mattson, Maclure has sued the government for wrongful dismissal and defamation of character.

Maclure, who holds UBC's prestigious chair in patient safety, describes the charges against him as "vague" and says the news of his firing struck him as "difficult to believe."

Legal complaints filed by three other ministry employees also fired in the affair - David Scott, Ramsay Hamdi and Roderick MacIsaac (who died in January under circumstances now under coroner's investigation) — are being pursued by the BC Government and Service Employees' Union.

Tensions over the use of data from BC's PharmaNet database to scrutinize drug sales and safety have been mounting for years. Last June, BC Information and Privacy Commissioner Elizabeth Denham met with a group of PharmaNet experts, including Dr. Bruce Carleton, a UBC pharmacology professor who, as chair of the Ministry of Health's Data Stewardship Committee, had significant influence over who gets drug data and for what purpose.

In a report on the meeting's outcome,
Denham concluded there is a "real and systemic" problem: "Researchers in British Columbia are simply not getting access to the health data they need to conduct medical research. This is unacceptable." Denham also complained of "data stewards with no efficient processes to approve data access requests and inefficient administration."

In January, Denham announced an investigation into the unauthorized disclosure of personal health data by the ministry that, alongside the seven legal proceedings underway, is expected to offer a reality check on the steps taken by MacDiarmid in the dismissals and limiting access to data. - Paul Christopher Webster, Toronto, Ont.

CMAJ 2013. DOI:10.1503/cmaj.109-4473 